\title{
Inhaltsübersicht.
}

\section{Erste Abteilung.}

\section{Kopf.}

I. Schädelgegend

Äussere Umhüllungen des Schälels

Knöchernes Schudelgewölbe

Grundfläche des Schädels

Hirnhăute und ihre Gefăbe

Gehirn. . . . . . . . . . . . . . . . . . 14

II. Augengegend . . . . . . . . . . . . . . . . 16

Augenhöhle . . . . . . . . . . . . . . . . . 16

Augenmuskeln . . . . . . . . . . . . . . . . 18

Auglider . . . . . . . . . . . . . . . . . . 18

'Thränenorgane . . . . . . . . . . . . . 20

GefäBe und Nerven der Angengegend . . . . . . . . 22

Augapfel . . . . . . . . . . . . . . . . . . 24

III. Nasengegend . . . . . . . . . . . . . . . . 24

ÄuBere Nase . . . . . . . . . . . . . . . . 24

Nasenhöhle . . . . . . . . . . . . . . . . . 25

IV. Gehörorgan . . . . . . . . . . . . . . . . 28

ÄuBeres Ohr. . . . . . . . . . . . . . . . . 28

Trommelfell und Paukenhöhle . . . . . . . . . . . . . . . 29

Tuba auditiva . . . . . . . . . . . . . . . . 31

V. Lippen- und Wangengegend . . . . . . . . . 33

Weichteile der Lippen und Wangen . . . . . . . . . 33

Oberkiefer . . . . . . . . . . . 39

Unterkiefer . . . . . . . . . . . 41

Zähne . . . . . . . . . . . . . 44 
VI. Gaumen. . . . . . . . . . 46

VII. Zunge

\section{Zweite Abteilung. \\ Hals.}

I. Vordere Hëlfte des Halses . . . . . . . . . . 51

Muskeln am Halse . . . . . . . . . . . . . . 52

Fascien an Halse . . . . . . . . . . . . . . 54

Arterien am Halse. . . . . . . . . . . . . . 55

Venen am Halse . . . . . . . . . . . . . . . . . 62

Nerven der Halsgegend . . . . . . . . . . . . 65

Zungenbein . . . . . . . . . . . . . . . . . 66

Kehlkopf . . . . . . . . . . . . . . . . . 67

luftröhre . . . . . . . . . . . . . . . . . . 73

Schild- und 'Thymusdrüse. . . . . . . . . . . . . . 74

Schlundkopf und Speiseröbre . . . . . . . . . .

II. Nackengegend

\section{Dritte Abteilung.}

Brust.

Brusturüse . . . . . . . . . . . . . . . . 83

Brustbeingegend . . . . . . . . . . . . . . . 84

Rippengegend . . . . . . . . . . . . . . . . . . 88

Rückengegend . . . . . . . . . . . . . . . 87

Zwerehfell . . . . . . . . . . . . . . . . . . . . . 89

Brusteingeweide . . . . . . . . . . . . . . . . 91

\section{Vierte Abteilung.}

Bauch.

I. Bauchwand .

Bauchrippen . . . . . . . . . . . . . . . . 93

Fascien und Muskeln der Bauchwand . . . . . . . . . 93

GefäBe und Nerven der Bauchwand . . . . . . . . . 96

Nabelring . . . . . . . . . . . . . . . . . . . . 98

Leistenkanal . . . . . . . . . . . . . . . . 100

Leistenbruch . . . . . . . . . . . . . . . 101

Schenkelring und Schenkelbruch . . . . . . . . . 105 
II. Bauchhöhle . . . . . . . . . . . . . . . . 112

Bauchfell . . . . . . . . . . . . . . . . 112

Netz . . . . . . . . . . . . . . . . 113

I,eber . . . . . . . . . . . 116

Gallenblase . . . . . . 116

Milz . . . . . . . . . . . 117

Pankreas . . . . . . . . . 118

Magen . . . . . . . . . . . . . . . . . 118

Dünndarın . . . . . . . . . . . . . . . . 119

Dickdarm . . . . . . . . . . . . . . . 119

Processus vermiformis . . . . . . . . . . . . . 121

Nieren . . . . . . . . 122

Aorta abdominalis . . . . . . . . . . . . . . 123

Arteriae iliacale . . . . . . . . . . . . . 123

Plexus lumbalis . . . . . . . . . . . . . . . . 124

Lymphdrüsen . . . . . . . . . . . . . . . . 125

\section{Fünfte Abteilung.}

Becken.

I. Wandung des Beckens . . . . . . . . . . . . . 125

Beckenknochen . . . . . . . . . . . . . . . 125

Weichteile der immeren Beckenwand . . . . . . . 127

Beckenbrüche . . . . . . . . . . . . . . . . . . . . 129

II. Mastdarm

III. Männliche Urin- und Geschlechtsorgane . . . . 133

Hoden und Sannenstrang . . . . . . . . . . . . 133

Blase . . . . . . . . . , . . . . . 136

Perinealgegend . . . . . . . . . . . . . . . 140

Harnröhre und l'rostat; . . . . . . . . . . . . 144

Penis. . . . . . . . . . . . . . 147

IV. Weibliche Geschlechtsteile . . . . . . . . . . 148

Weibliche Blase und Harnröhre . . . . . . . . . 148

ÄuBere G'eschlechtsteile . . . . . . . . . . . . 150

Scheide . . . . . . . . . . . . . . . . . . 151

Uterus . . . . . . . . . . . . . . . . . 152

Eierstock . . . . . . . . . . . . . 154

\section{Sechste Abteilung.}

Obere Extremität.

Vordere Schulter- und Achselgegend . . . . . . . 155

Schlïsselbein . . . . . . . . . . . . 160 
Iohaltsübersicht.

Schulterblatt, hintere schuitergegend .

Schultergelenk . . . . . . . . . . . . . . . 163

Oberarm . . . . . . . . . . . . . . . . . 168

Ellbogengegend . . . . . . . . . . . . . . . 171

Vorderarm . . . . . . . . . . . . . . . . . 176

Gegend des Handgelenks . . . . . . . . . . . 179

Gelenke der Handwurzelgegend . . . . . . . . 183

Mittelhand . . . . . . . . . . . . . . . . . 185

Finger . . . . . . . . . . . . . . . . . . 188

\section{Siebente Abteilung.}

Untere Extremitit.

Hüftgelenksgegend . . . . . . . . . . . . . . 192

Mittlere Schenkelgegend . . . . . . . . . . . . 204

Kniegegend . . . . . . . . . . . . . . . . . 208

Unterschenkel . . . . . . . . . . . . . . . . . 217

Talocruralgelenk . . . . . . . . . . . . . . . 223

Talotarsalgelenk . . . . . . . . . . . . . . . . . . 227

MittelfuB und Zehen . . . . . . . . . . . . . . 230

Übersicht der von der Anatomischen Gesellschaft angenommenen neuen Nomenclatur nebst den bisher gebräuchlichen Bezeichnungen . . . . . . . . 234 